\title{
Correlation of EGFR, IDH1 and PTEN status with the outcome of patients with recurrent glioblastoma treated in a phase II clinical trial with the EGFR-blocking monoclonal antibody cetuximab
}

\author{
SHASHA LV ${ }^{1}$, ERIK TEUGELS ${ }^{1}$, JAN SADONES ${ }^{1,2}$, SYLVIA DE BRAKELEER $^{1}$, JOHNNY DUERINCK ${ }^{1,4}$, \\ STEPHANIE DU FOUR ${ }^{1,4}$, ALEX MICHOTTE ${ }^{2,3}$, JACQUES DE GRÈVE ${ }^{1}$ and BART NEYNS ${ }^{1}$ \\ ${ }^{1}$ Laboratory of Molecular Oncology and Department of Medical Oncology, Departments of ${ }^{2}$ Pathology, \\ ${ }^{3}$ Pathology and Neuropathology and ${ }^{4}$ Neurosurgery, University Hospital Brussels, \\ Free University Brussels, 1090 Brussels, Belgium
}

Received March 9, 2012; Accepted April 27, 2012

DOI: 10.3892/ijo.2012.1539

\begin{abstract}
Mutation and gene amplification of the epithelial growth factor receptor (EGFR) is one of the most common genetic alterations in glioblastoma (GB). EGFR is, therefore, an attractive molecular target for the treatment of GB. EGFRtargeted therapies however have been largely ineffective in clinical trials. In this study, we investigated the correlation between the EGFR gene amplification status, expression of the EGFR variant III (EGFRvIII) and EGFR variant IV (EGFRvIV) mutations, expression of the phosphatase and tensin homologue gene on chromosome 10 (PTEN) and mutation of the isocitrate dehydrogenase 1 (IDH1) gene and the survival of patients suffering from recurrent glioblastoma who were treated with the EGFR-targeted monoclonal antibody cetuximab in a prospective phase II clinical trial. EGFR amplification was detected in 19 out of 35 GB (54\%), EGFRvIII expression in 11 (31.4\%) and EGFRvIV expression in 7 (20\%). The EGFRvIII and EGFRvIV mutations were exclusively found in GB with EGFR amplification and were almost mutually exclusive with IDH1 mutation (EGFRvIII mutation was found in 1 out of 11 GB with an IDH1 mutation). Patients with an EGFR amplification lacking EGFRvIII expression had a significantly superior progression free survival (PFS) and a numerical better overall survival (OS) following treatment with cetuximab [median PFS 3.03 vs. 1.63 months ( $\mathrm{p}=0.006$ ); median OS 5.57 vs. 3.97 months $(\mathrm{p}=0.12)]$. Within the subgroup of patients with EGFR amplification, patients with EGFRvIII positive glioblastoma had a worse survival [median PFS 1.63 vs. 3.03 months ( $\mathrm{p}=0.01$ ); median
\end{abstract}

Correspondence to: Dr Bart Neyns, Medical Oncology, University Hospital Brussels, Free University Brussels, Laarbeeklaan 101, 1090 Brussels, Belgium

E-mail: bart.neyns@uzbrussel.be

Key words: epithelial growth factor receptor amplification, epithelial growth factor receptor variant III, epithelial growth factor receptor variant IV, isocitrate dehydrogenase 1 , phosphatase and tensin homologue gene on chromosome 10, glioblastoma, cetuximab
OS 3.27 vs. 5.57 months $(\mathrm{p}=0.08)]$. Our observations indicate that the type of EGFR mutation may determine the outcome of GB patients treated with cetuximab. Prospective investigation of both the EGFR amplification and mutation status in clinical trials with EGFR-targeted therapies for GB is indicated.

\section{Introduction}

Glioblastoma (GB, WHO grade IV glioma) and anaplastic gliomas (WHO grade III gliomas) are lethal brain tumors for which only limited therapeutic options exist. The standard treatment for high-grade gliomas (WHO grade III and IV) consists of a maximal safe surgical resection followed by adjuvant radiotherapy. While concomitant temozolomide during the radiation therapy followed by six cycles of adjuvant chemotherapy improves the survival of patients with GB, the role of chemotherapy in the initial treatment of anaplastic glioma remains to be defined (1).

Clinically relevant molecular subtypes of GB have recently been identified (2). A small proportion of GB are characterized by mutation of the isocitrate dehydrogenase 1 and -2 (IDH1 and -2) genes, a genotype that is most frequently found in low-grade and anaplastic gliomas (3). Genomic alterations of the epidermal growth factor receptor (EGFR) gene play a crucial role in pathogenesis of a subgroup of GB (4). The most common gain-of-function alterations for EGFR in GB are mutation, amplification, and overexpression $(5,6)$. Expression of a constitutively phosphorylated EGFR-mutant, EGFR variant III (EGFRvIII), is found in approximately 20\%-30\% of GB patients. EGFRvIII has an in-frame deletion of exons 2-7 resulting in the loss of the amino acid residues that contribute to the ligand binding area. Consequently, EGFRvIII causes ligandindependent constitutive activation of downstream signaling pathways such as the Mitogen-activated protein kinase (MAPK) pathway that contributes to the malignant phenotype (7-9). In vitro studies have demonstrated that expression of EGFRvIII leads to a growth and survival advantage in several types of cancer cells (10-13). Another frequent EGFR mutant in GB is the EGFR variant IV (EGFRvIV), which has a genomic truncation of the carboxyl-terminus domain (CTD, exon 25, 26 and 27 in EGFRvIVa or exon 25 and 26 in EGFRvIVb) $(14,15)$. Both 
EGFRvIV variants have a transforming capacity in vitro and in animals (16). Furthermore, a novel deletion mutation with the transforming capacity was found also in EGFR CTD which is the deletion of exon 27 (17).

In high-grade gliomas, the EGFRvIII and EGFRvIV mutations have been found exclusively in association with EGFR gene amplification $(18,19)$. Expression of EGFRvIII identifies a particular subtype of anaplastic astrocytoma with a poor prognosis. In the global GB-population this correlation with survival is less distinct (20-24). However, within the subpopulation of GB patients with EGFR amplification, a strong correlation was reported between EGFRvIII expression and a poor overall survival (4). No study has yet reported a correlation between EGFRvIV expression and survival of GB patients.

The importance of EGFRvIII expression as a predictive marker for anti-EGFR therapies has been a matter of debate. Co-expression of EGFRvIII and a phosphatase and tensin homologue on chromosome 10 (PTEN) was reported to be a significant predictor of responsiveness to small molecule EGFR kinase inhibitors in retrospectively identified GB patients benefitting from such therapy (25). Furthermore, concomitant EGFRvIII expression and loss of PTEN were shown to synergistically induce genomic instability in vitro and result in enhanced tumor formation (26). In additional studies it was reported that EGFR amplification and protein kinase B/akt activation to predict the response to treatment with a small molecule EGFR kinase inhibitor in GB patients (27-28). These findings were however not confirmed in a prospective randomized study with erlotinib (29).

In vitro data indicate that cetuximab is able to bind to and down regulate EGFRvIII. This may however not be sufficient to inhibit the proliferation of the glioma cells (30). Other observations have indicated that cetuximab not only reduced the phosphorylated EGFRvIII but also inhibited significantly the proliferation of EGFRvIII expressing cells (31). Moreover, cetuximab proved to be active in animal models with EGFR amplified GB (32). In addition, radiation and chemotherapeutic agents augmented the effect of cetuximab on GB cells in vitro and in vivo (33). Recently, the anti-tumor activity of cetuximab against EGFR CTD-mutant GB in both cells and animals was reported (17).

We have previously reported the results of a stratified 2-arm prospective phase II clinical trial of recurrent high-grade glioma patients treated with the EGFR monoclonal antibody cetuximab. A numerically superior outcome, not reaching statistical significance, was found in patients with EGFR gene amplification (34). In this work, we have further investigated the correlation between EGFR amplification, EGFRvIII and EGFRvIV expression, PTEN expression, and IDH1 mutation status and the survival of patients treated with cetuximab in this clinical trial.

\section{Materials and methods}

Patients and tumor material. Tumor material was obtained from 35 patients with recurrent high-grade glioma who participated in the prospective phase II trial (34). Tumor tissues were obtained during therapeutic resections performed before the time of study participation. Tumor sections with a thickness of $4 \mu \mathrm{m}$ were used for $\mathrm{H} \& \mathrm{E}$ staining and centralized review of tumor histopathology and grading according to WHO 2007 criteria (35).

EGFR and IDH1 molecular analysis. The IDH1 mutation status was assessed with a PCR-DGGE-Sequencing system as reported previously (36). The amplification status of EGFR was assessed by FISH, as described in the report on the clinical trial with cetuximab (34).

For the molecular analysis of EGFRvIII, formalin-fixed paraffin-embedded (FFPE) tissue blocks were sectioned at a thickness of $10 \mu \mathrm{m}$ (3 sections for RNA isolation). As a positive control an EGFRvIII transfected U87 cell line, obtained from Professor Webster Cavenee (Ludwig Institute for Cancer Research, University of California, San Diego, CA, USA), was used (10). Tissues were dewaxed by xylene and ethanol. The total RNA was isolated from tumor sections using the RNeasy FFPE kit (Qiagen, Venlo, Netherlands) according to the manufacturer's instructions with modifications by changing the incubation time after mixing with proteinase $\mathrm{K}$ for $36 \mathrm{~h}$ at $55^{\circ} \mathrm{C}$, meanwhile, adding proteinase $\mathrm{K}$ every $12 \mathrm{~h}$. Depending on the size of the tumor sample, the RNA ranged from 0.02 to $2 \mu \mathrm{g}$ (Nanodrop2000, Thermo Scientific, Wilmington, DE, USA). The RNA isolation of the positive control cell line (U878) was performed with the Absolute RNA Wash Solution (Applied Biosystems, Carlsbad, CA, USA). The reverse transcription was accomplished using the SuperScript ${ }^{\circledR}$ II Reverse Transcriptase (Invitrogen) according to the manufacturer's protocol. The entire cDNA sample was treated with Ribonuclease H (Invitrogen, Ghent, Belgium) to eliminate the residual RNA after reverse transcription.

Two pairs of primers for EGFRvIII were derived from the previous reference to perform a hemi-nested PCR (19) with some modifications. For the first step PCR, a forward primer GAGCT CTTCGGGGAGCAG and a reverse primer TCCTCCATCTCA TAGCTGTCG were used to generate a $178 \mathrm{bp}$ fragment that span the junctions of the deletion c.158_1136del. A standard PCR Master mix (25 $\mu \mathrm{l}$ in total) is composed of cDNA $(1 \mu \mathrm{l})$, $1 \mathrm{X}$ PCR buffer, $1 \mu \mathrm{g} / \mu \mathrm{l}$ bovine serum albumin (BSA), $0.8 \mathrm{mM}$ dNTPs, $0.025 \mathrm{U} / \mu 1$ Taq DNA polymerase (Qiagen, $5 \mathrm{U} / \mu \mathrm{l}$ ) and $2 \mathrm{ng} / \mu \mathrm{l}$ of each primer. The reaction was run for 35 cycles denaturation at $94^{\circ} \mathrm{C}$ for $1 \mathrm{~min}$, annealing at $64^{\circ} \mathrm{C}$ for $1 \mathrm{~min}$ and extension at $72^{\circ} \mathrm{C}$ for $1 \mathrm{~min}$. During the second step, a $131 \mathrm{bp}$ fragment was amplified 25 cycles using $1 \mu \mathrm{l}$ of product from the first step PCR with the forwards primer GAGCTCTTCGGGG AGCAG and the reverse primer GTGATCTGTCACCACATA ATTACCTTTCT. All other PCR conditions were the same as step 1 . The final PCR product was visualized on a $2 \%$ agarose gel and confirmed by sequencing (ABI 310 Genetic Analyzer, Applied Biosystems, Foster city, CA, USA) after purification with the High Pure PCR Product Purification kit (Roche, Penzberg, Germany). The analysis of each sample was performed in triplicate. EGFRvIV mutation analysis was performed with the same method as EGFRvIII.

Immunohistochemistry of PTEN. PTEN expression was evaluated by immunohistochemistry on $4 \mu \mathrm{m}$ FFPE tissue sections by using a rabbit IgG monoclonal antibody (1:100 dilution, PTEN, 138G6, Cell Signaling Technology Inc., Beverly, MA, USA) and an anti-rabbit IgG secondary antibody (ultraView Universal DAB Detection Kit, Ventana Medical Systems Inc., 
Table I. Summary of clinical and molecular characteristics.

\begin{tabular}{|c|c|}
\hline Characteristic $(\mathrm{N}=35)$ & $\mathrm{N}$ \\
\hline $\operatorname{Sex}, M / F$ & $22 / 13$ \\
\hline Median age, range & $54,33-73$ \\
\hline $\begin{array}{l}\text { Histology at first diagnosis } \\
\text { WHO grade II and III glioma } \\
\text { WHO grade IV, de novo GB }\end{array}$ & $\begin{array}{c}9 \\
26\end{array}$ \\
\hline $\begin{array}{l}\text { Histology at recurrence } \\
\text { WHO grade II and III glioma } \\
\text { WHO grade IV, secondary GB } \\
\text { WHO grade IV, de novo GB }\end{array}$ & $\begin{array}{c}3 \\
6 \\
26\end{array}$ \\
\hline $\begin{array}{l}\text { KPS at recurrence } \\
100 \\
90-80 \\
70-60\end{array}$ & $\begin{array}{c}3 \\
10 \\
22\end{array}$ \\
\hline $\begin{array}{l}\text { EGFR amplification status } \\
\text { Amplification } \\
\text { Wild-type }\end{array}$ & $\begin{array}{l}19 \\
16\end{array}$ \\
\hline $\begin{array}{l}\text { EGFRvIII status } \\
\text { Mutation } \\
\text { Wild-type }\end{array}$ & $\begin{array}{l}11 \\
24\end{array}$ \\
\hline $\begin{array}{l}\text { EGFRvIV status } \\
\text { Mutation } \\
\text { Wild-type }\end{array}$ & $\begin{array}{c}7 \\
28\end{array}$ \\
\hline $\begin{array}{l}\text { IDH1 status } \\
\text { Mutation } \\
\text { Wild-type }\end{array}$ & $\begin{array}{c}6 \\
29\end{array}$ \\
\hline $\begin{array}{l}\text { PTEN status }(\mathrm{N}=31) \\
\text { Positive } \\
\text { Negative }\end{array}$ & $\begin{array}{c}6 \\
25\end{array}$ \\
\hline
\end{tabular}

$\mathrm{N}$, number of patients; GB, glioblastoma; EGFRvIII, epidermal growth factor receptor variant III; EGFRvIV, epidermal growth factor receptor variant IV; IDH1, isocitrate dehydrogenase 1; PTEN, phosphatase and tensin homologue.

Tucson, AZ, USA) according to the manufacturer's protocol. Immunoreactivity was visualized with a DAB solution provided in the kit (ultraView Universal DAB Detection Kit, Ventana Medical Systems Inc.). Positive controls were visualized on the same sections with epithelial cells and neurons. PTEN staining was both nuclear and cytoplasmic and was evaluated with a twoscore system including intensity and percentage of positive cells as described (37).

Clinical data and survival analysis. Clinical information was collected from each patient to investigate possible correlation between EGFRvIII mutation status and clinical parameters including glioma WHO grade, age, date of birth, date of initial diagnosis and of recurrence, date of progression and date of death or last contact. Kaplan-Meier survival analysis was used to examine the correlation between molecular baseline factors and survival data. We also analyzed the association between EGFRvIII, EGFRvIV, PTEN expression, EGFR amplification and IDH1 mutation.
Table II. Correlation between molecular markers

\begin{tabular}{|c|c|c|c|c|}
\hline & \multicolumn{4}{|c|}{ EGFRvIII } \\
\hline & \multicolumn{2}{|c|}{+} & \multicolumn{2}{|c|}{-} \\
\hline & \multicolumn{2}{|c|}{$\begin{array}{c}\text { IDH1 } \\
\text { mutation }\end{array}$} & \multicolumn{2}{|c|}{$\begin{array}{c}\text { IDH1 } \\
\text { mutation }\end{array}$} \\
\hline & + & - & + & - \\
\hline \multicolumn{5}{|c|}{$\mathrm{N}=31$ EGFR amplification } \\
\hline \multirow[t]{2}{*}{$+\quad$ PTEN } & 0 & 2 & 0 & 2 \\
\hline & 1 & 8 & 1 & 5 \\
\hline \multirow[t]{2}{*}{ - PTEN } & 0 & 0 & 0 & 2 \\
\hline & 0 & 0 & 2 & 8 \\
\hline \multicolumn{5}{|c|}{$\mathrm{N}=35$ EGFR amplification } \\
\hline \multirow{2}{*}{+ EGFRvIV + } & 0 & 5 & 0 & 2 \\
\hline & 1 & 5 & 1 & 5 \\
\hline \multirow{2}{*}{$\begin{array}{r}\text { - EGFRvIV + } \\
\text { - }\end{array}$} & 0 & 0 & 0 & 0 \\
\hline & 0 & 0 & 4 & 12 \\
\hline
\end{tabular}

$\mathrm{N}$, number of patients available; EGFRvIII, epidermal growth factor receptor variant III; EGFRvIV, epidermal growth factor receptor variant vIV; IDH1, isocitrate dehydrogenase 1, + mutation, - wild-type; PTEN, phosphatase and tensin homologue, + expression, - loss.

\section{Results}

Analysis of EGFR gene amplification, EGFRvIII-, EGFRvIV-RNA expression, and PTEN-protein expression and IDH1 mutation status. EGFR amplification, EGFRvIII-, and EGFRvIV expression were detected in, respectively 19/35 (54\%), $11 / 35(31 \%)$ and 7/35 (20\%, EGFRvIVa in 5/7 and EGFRvIVb in 2/7) of the gliomas (Fig. 1, Table I). EGFRvIII and EGFRvIV expression were exclusively found in patients with an EGFR amplification $(11 / 19,58 \% ; 7 / 19,37 \%)$. EGFRvIII was most frequently found in de novo GBs $(9 / 26,35 \%)$, and less frequently in secondary GBs and grade II or III glioma (2/9, 22\%). Likewise, EGFRvIV was detected in 6/26 (23\%) de novo GB and 1/9 (11\%) of the anaplastic astrocytoma.

IDH1 mutation was found in 6/35 (17\%) patients (Table I) and correlated with a younger age at first diagnosis, and a histological diagnosis of low-grade or secondary GB. IDH1 mutation was only rarely found in association with an EGFR amplification or expression of EGFRvIII and EGFRvIV (2/19 patients with EGFR amplification, 1/11 patients with EGFRvIII and 0/7 patients with EGFRvIV were found with a concomitant IDH1 mutation, Table II).

Strong positive IHC staining for PTEN expression was observed in 6 out of the 31 tested gliomas (Table I; Fig. 2) and found only in WHO grade IV gliomas ( $5 / 6$ de novo GB and $1 / 6$ secondary GB). Of these 6 patients with a PTEN positive de novo GB, 4 had an EGFR amplification, two of which also expressed EGFRvIII, none of them had EGFRvIV and all 6 patients had an IDH1 wild-type status (Table II). No significant correlation was found between PTEN expression and clinical baseline characteristics such as age, gender and performance status. 
Table III. Correlation between EGFRvIII status and PFS or OS after cetuximab treatment in different patients' cohorts.

\begin{tabular}{|c|c|c|c|}
\hline & $\mathrm{N}$ & PFS (months) & OS (months) \\
\hline Total pts. cohort & 35 & & \\
\hline Media (95\% CI: range) & & $1.83(1.56,2.09)$ & $4.80(3.95,5.64)$ \\
\hline \multicolumn{4}{|l|}{ EGFR amplification } \\
\hline Pts. with EGFR amplification & & 2.10 & 4.73 \\
\hline Pts. without EGFR amplification & & 1.63 & 4.80 \\
\hline P-value & & 0.09 & 0.69 \\
\hline \multicolumn{4}{|l|}{ EGFRvIII } \\
\hline Pts. with EGFRvIII & 11 & 1.63 & 3.27 \\
\hline Pts. without EGFRvIII & 24 & 1.93 & 4.93 \\
\hline P-value & & 0.21 & 0.21 \\
\hline \multicolumn{4}{|l|}{ EGFR amplification and EGFRvIII } \\
\hline Pts. with EGFR amplification but without EGFRvIII & 8 & 3.03 & 5.57 \\
\hline Others pts. & 27 & 1.63 & 3.97 \\
\hline P-value & & 0.006 & 0.12 \\
\hline Pts. with EGFR amplification cohort & 19 & & \\
\hline Media (95\% CI: range) & & $2.10(1.67,2.52)$ & $4.73(3.69,5.76)$ \\
\hline \multicolumn{4}{|l|}{ EGFRvIII } \\
\hline Pts. with EGFRvIII & 11 & 1.63 & 3.27 \\
\hline Pts. without EGFRvIII & 8 & 3.03 & 5.57 \\
\hline P-value & & 0.01 & 0.08 \\
\hline
\end{tabular}

$\mathrm{N}$, number of patients; PFS, progression free survival; OS, overall survival from cetuximab treatment; Pts., patients; EGFRvIII, epidermal growth factor receptor variant III; PTEN, phosphatase and tensin homologue.

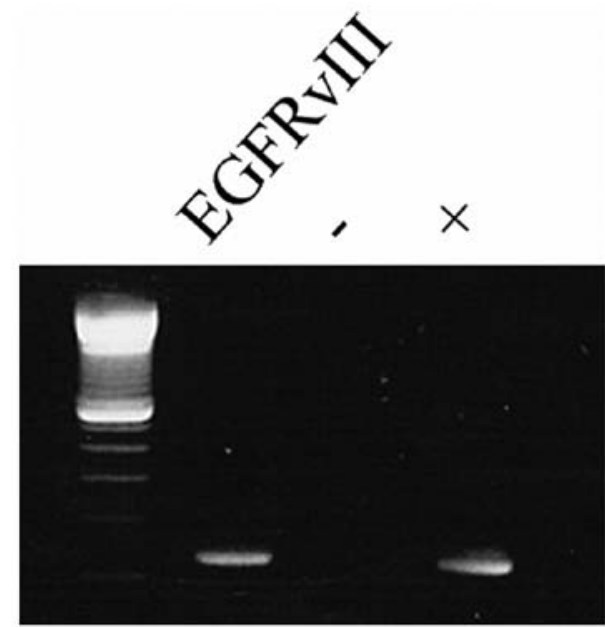

Figure 1. PCR product migration pattern of EGFRvIII corresponding to the EGFRvIII with negative and positive control on $2 \%$ agarose gel.

Correlation between molecular markers and the survival of patients treated with cetuximab. At the time of this analysis, 34 out of 35 patients died, all because of tumor progression; one patient was lost to follow-up. The median overall survival (OS) and median progression free survival (PFS) from the time of recruitment to the clinical trial were respectively 4.8 months (95\% CI: 3.9-5.6) and 1.8 months (95\% CI: 1.5-2.0) (Table II).

In our previous report on this phase II trial, EGFR amplification was found to correlate with a numerical superior PFS and OS in patients treated with cetuximab (34). In this updated subgroup analysis, the correlation between EGFR amplification and superior survival of patients was still present for PFS [median PFS 2.10 in patients with EGFR amplification vs. 1.63 in patients with wild-type EGFR ( $\mathrm{p}=0.09)$ ] (Fig. 3A), however, was no longer found for OS (median OS 4.73 in patients with EGFR amplification vs. 4.80 in patients with wild-type EGFR, $p=0.69$ ). A numerically worse survival (PFS and OS) was observed for patients with expression of EGFRvIII but this difference did not reach the level of statistical significance [median PFS of 1.63 vs. 1.93 months $(\mathrm{p}=0.21)$ and median OS of 3.27 vs. 4.93 months $(\mathrm{p}=0.21)$ ] (Fig. 3B and C). A better PFS and OS were found for patients with EGFR amplification lacking EGFRvIII expression [median PFS of 3.03 vs. 1.63 months $(\mathrm{p}=0.006)$; median OS of 5.57 vs. 3.97 months $(\mathrm{p}=0.12)$ ] (Fig. 3D and $\mathrm{E})$. When analyzed within the cohort of patients with EGFR amplification $(n=19)$, expression of EGFRvIII correlated significantly with a worse outcome in survival [median PFS 1.63 vs. 3.03 months $(p=0.01)$; median OS 3.27 vs. 5.57 months $(\mathrm{p}=0.08)$ ] (Fig. 3F and $\mathrm{G})$.

In univariate analysis, EGFRvIV mutation and PTEN expression were not correlated with the survival of the total population or within the subgroup of EGFR-amplified GBs.

\section{Discussion}

In this study of 35 patients with recurrent high-grade gliomas treated with the EGFR monoclonal antibody cetuximab, we find that EGFRvIII/vIV expression is restricted to patients with EGFR amplification, confirming prior reports in the literature. EGFRvIII and EGFRvIV expression were rarely found in patients with an IDH1 mutation (1/6 and 0/6), again confirming 

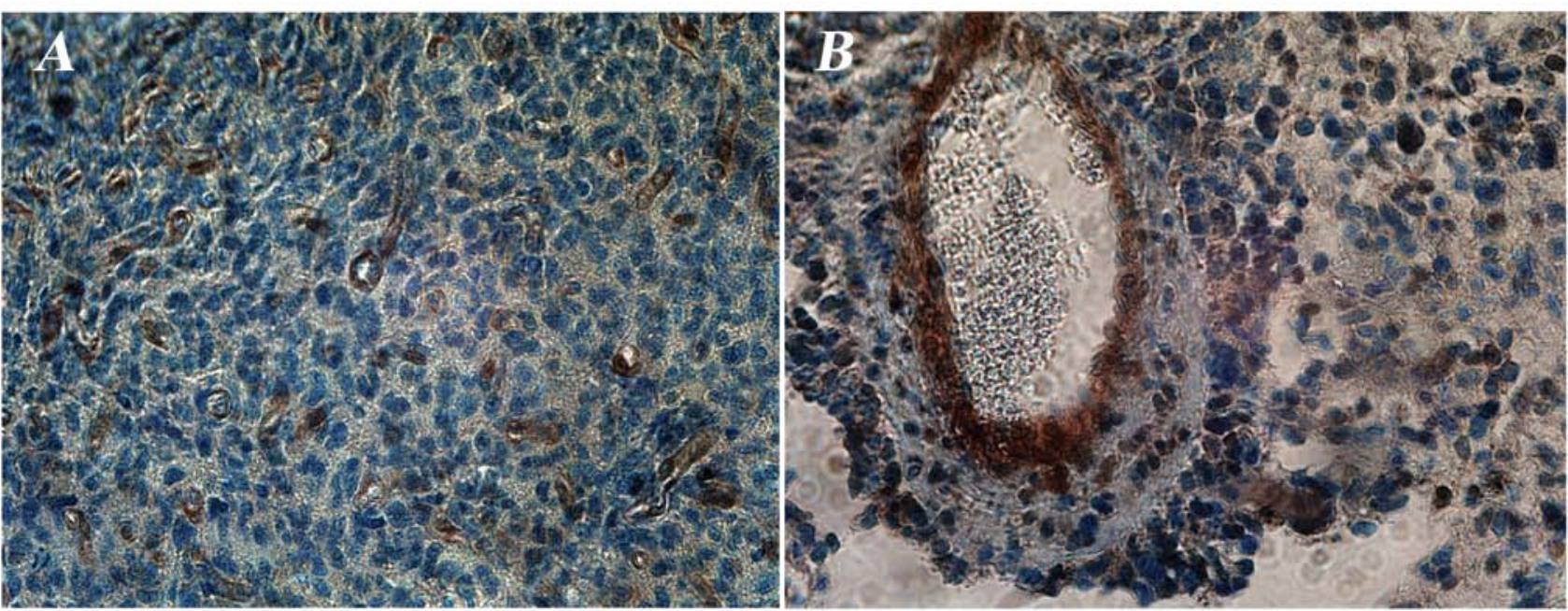

Figure 2. Immunohistochemistry images of PTEN. (A and B) PTEN negative and positive staining on glioma tissues.
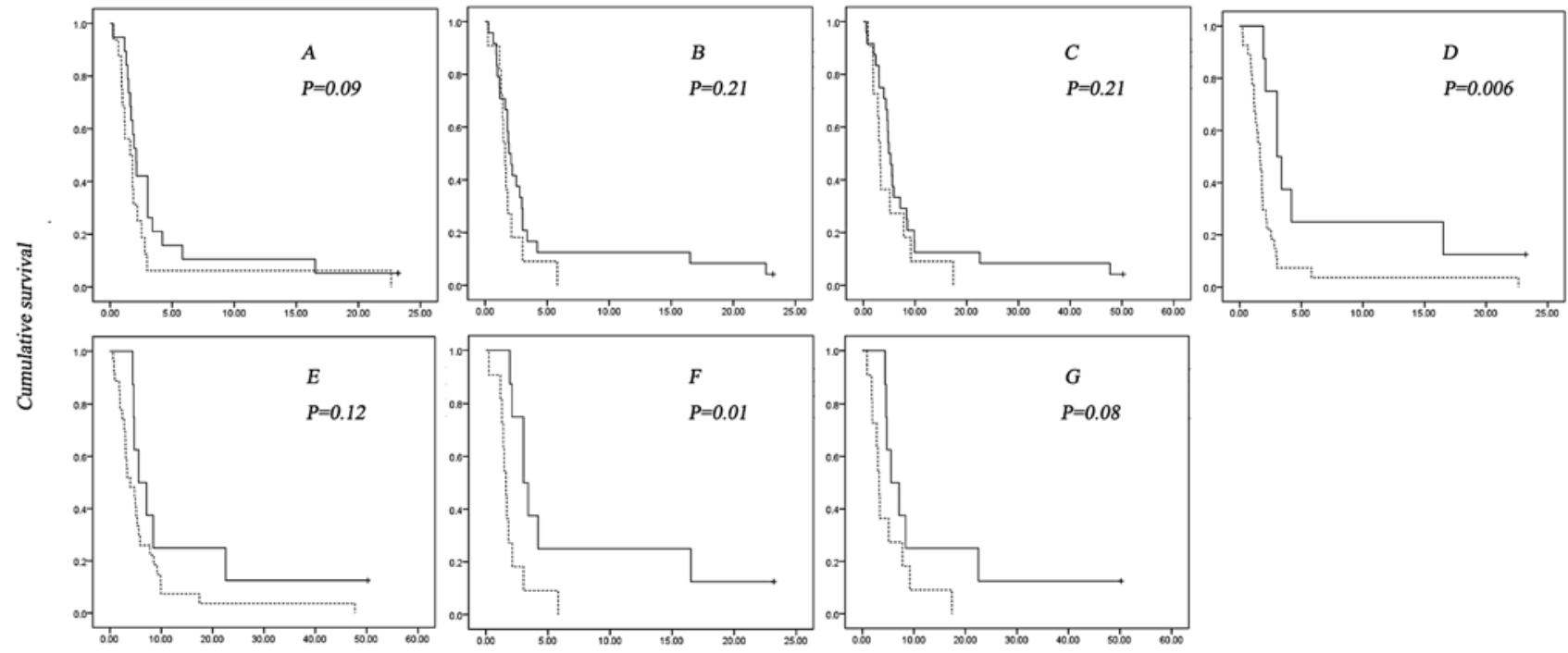

Time (months)

Figure 3. Kaplan-Meier survival estimates (p-value according to the Log-rank test). (A) Progression free survival (PFS) from the time of cetuximab treatment on EGFR amplification status in the global study population $(\mathrm{p}=0.09)$, solid line, EGFR amplification; dash line, EGFR wild-type; +, censored. (B and C) PFS and OS from the time of treatment of cetuximab in global population EGFRvIII status ( $\mathrm{p}=0.21$ and 0.21 ), solid line, EGFRvIII negative; dash line, EGFRvIII positive; + , censored. (D and E) PFS and OS from the time of treatment of cetuximab in global population based on EGFR amplification/EGFRvIII status ( $\mathrm{p}=0.006$ and 0.12 ), solid line, EGFR amplification without EGFRvIII; dash line, others; +, censored. (F and G) PFS and OS from the time of treatment of cetuximab in cohort of patients with EGFR amplification based on EGFRvIII status ( $\mathrm{p}=0.01$ and 0.08 ), solid line, EGFRvIII negative; dash line, EGFRvIII positive; +, censored.

the previous reports on the association of IDH1 mutation with WHO grade II and III glioma and secondary GB (3) and EGFR amplification/mutation with de novo GB (38).

Overall treatment with cetuximab has low activity against recurrent GB but shows a trend towards a higher activity in patients with EGFR-amplified GB, as was reported in our initial clinical study report (34). In this molecular sub-study we investigated the potential influence of specific EGFR-mutants and found that the expression of EGFRvIII correlated with a significantly worse survival in the cohort of patients with an EGFR amplification in our study. Similar observations have been reported previously (4). Since we observed that, the PFS of patients treated with cetuximab was significantly superior in patients with EGFR gene amplification but without EGFRvIII expression, we hypothesize that EGFR amplification without EGFRvIII may identify a subpopulation with a higher sensitivity for cetuximab. Given the single-arm study design, we however cannot exclude a naturally worse prognosis of EGFRvIII mutant GB among patients with EGFR-amplified tumors.

Although it was reported that cetuximab showed effective inhibition to EGFR CTD deletion mutation in glioblastoma cells and animal models (17), we did not find a correlation between EGFRvIV deletion and survival of patients in our study in total population or any sub-cohort. We can however not exclude that this is related to the small sample size of patients with an EGFRvIV mutated GB in our study. 
In the literature, PTEN expression detected by IHC has been reported in about $62 \%$ of primary glioma (39) and in $17 \%$ of recurrent GB (40). PTEN expression as detected by IHC is also more frequently found in low-grade glioma as compared to high-grade glioma. We detected a positive PTEN expression in $21 \%$ of high-grade glioma (in $19 \%$ of the whole population), which is comparable with the data in the literature. It was previously reported that coexpression of EGFRvIII and PTEN was a predictor for response to EGFR inhibitors in patients with recurrent GB (25). In this study only two patients were found with combined EGFRvIII and PTEN expression making it impossible to assess this correlation. A study with larger sample size would be needed to assess the role of EGFRvIII and PTEN in survival of glioma patients treated with cetuximab at recurrence.

In summary, within the recurrent glioma patients who were treated with cetuximab we have confirmed that EGFR mutation is exclusively present in patients with EGFR amplification. In addition, we have found a particularly favorable survival for the sub-group of patients with EGFR amplification, but without EGFRvIII expression. Our study supports further documentation of both the glioma EGFRvIII expression and amplification status in studies with cetuximab.

\section{Acknowledgements}

This study was supported by the Free University Brussels (VUB)/the Chinese Scholarship Council (CSC) PhD program. We gratefully acknowledge the supply of U87/EGFRvIII cell from Professor Webster Cavenee (Ludwig Institute for Cancer Research, University of California, San Diego, CA, USA). We thank Mr. Kurt De Neef (Laboratory of Molecular Oncology, Free University Brussels, Belgium), Mr. Pascal Verhavert, Mr. Tim Walravens and Miss Sara Laceur (Pathology Department, University Hospital Brussels, Belgium) for their technical help. We also thank Miss Katrien Van den Bossche (data manager, University Hospital Brussels, Belgium) for her assistance and help. Bart Neyns has received research funding from Merck.

\section{References}

1. Stupp R, Hegi ME, Mason WP, van den Bent MJ, Taphoorn MJ, Janzer RC, Ludwin SK, Allgeier A, Fisher B, Belanger K, Hau P, Brandes AA, Gijtenbeek J, Marosi C, Vecht CJ, Mokhtari K, Wesseling P, Villa S, Eisenhauer E, Gorlia T, Weller M, Lacombe D, Cairncross JG, Mirimanoff RO, European Organisation for Research and Treatment of Cancer Brain Tumour and Radiation Oncology Groups and National Cancer Institute of Canada Clinical Trials Group: Effects of radiotherapy with concomitant and adjuvant temozolomide versus radiotherapy alone on survival in glioblastoma in a randomised phase III study: 5-year analysis of the EORTC-NCIC trial. Lancet Oncol 10: 459-466, 2009.

2. Verhaak RG, Hoadley KA, Purdom E, Wang V, Qi Y, Wilkerson MD, Miller CR, Ding L, Golub T, Mesirov JP, Alexe G, Lawrence M, O'Kelly M, Tamayo P, Weir BA, Gabriel S, Winckler W, Gupta S, Jakkula L, Feiler HS, Hodgson JG, James CD, Sarkaria JN, Brennan C, Kahn A, Spellman PT, Wilson RK, Speed TP, Gray JW, Meyerson M, Getz G, Perou CM, Hayes DN and Cancer Genome Atlas Research Network: Integrated genomic analysis identifies clinically relevant subtypes of glioblastoma characterized by abnormalities in PDGFRA, IDH1, EGFR and NF1. Cancer Cell 17: $98-110,2010$.
3. Yan H, Parsons DW, Jin G, McLendon R, Rasheed BA, Yuan W, Kos I, Batinic-Haberle I, Jones S, Riggins GJ, Friedman H, Friedman A, Reardon D, Herndon J, Kinzler KW, Velculescu VE, Vogelstein B and Bigner DD: IDH1 and IDH2 mutations in gliomas. N Engl J Med 360: 765-773, 2009.

4. Shinojima N, Tada K, Shiraishi S, Kamiryo T, Kochi M, Nakamura H, Makino K, Saya H, Hirano H, Kuratsu J, Oka K, Ishimaru Y and Ushio Y: Prognostic value of epidermal growth factor receptor in patients with glioblastoma multiforme. Cancer Res 63: 6962-6970, 2003.

5. Ekstrand AJ, James CD, Cavenee WK, Seliger B, Pettersson RF and Collins VP: Genes for epidermal growth factor receptor, transforming growth factor alpha, and epidermal growth factor and their expression in human gliomas in vivo. Cancer Res 51: 2164-2172, 1991

6. Wikstrand CJ, McLendon RE, Friedman AH and Bigner DD: Cell surface localization and density of the tumor-associated variant of the epidermal growth factor receptor, EGFRvIII. Cancer Res 57: 4130-4140, 1997.

7. Ekstrand AJ, Longo N, Hamid ML, Olson JJ, Liu L, Collins VP and James CD: Functional characterization of an EGF receptor with a truncated extracellular domain expressed in glioblastomas with EGFR gene amplification. Oncogene 9: 2313-2320, 1994.

8. Huang PH, Xu AM and White FM: Oncogenic EGFR signaling networks in glioma. Sci Signal 2: re6, 2009.

9. Wheeler SE, Suzuki S, Thomas SM, Sen M, Leeman-Neill RJ, Chiosea SI, Kuan CT, Bigner DD, Gooding WE, Lai SY and Grandis JR: Epidermal growth factor receptor variant III mediates head and neck cancer cell invasion via STAT3 activation. Oncogene 29: 5135-5145, 2010.

10. Nishikawa R, Ji XD, Harmon RC, Lazar CS, Gill GN, Cavenee WK and Huang HJ: A mutant epidermal growth factor receptor common in human glioma confers enhanced tumorigenicity. Proc Natl Acad Sci USA 91: 7727-7731, 1994.

11. Tang CK, Gong XQ, Moscatello DK, Wong AJ and Lippman ME: Epidermal growth factor receptor vIII enhances tumorigenicity in human breast cancer. Cancer Res 60: 3081-3087, 2000.

12. Theys J, Jutten B, Dubois L, Rouschop KM, Chiu RK, Li Y, Paesmans K, Lambin P, Lammering G and Wouters BG: The deletion mutant EGFRvIII significantly contributes to stress resistance typical for the tumour microenvironment. Radiother Oncol 92: 399-404, 2009.

13. Sok JC, Coppelli FM, Thomas SM, Lango MN, Xi S, Hunt JL, Freilino ML, Graner MW, Wikstrand CJ, Bigner DD, Gooding WE, Furnari FB and Grandis JR: Mutant epidermal growth factor receptor (EGFRvIII) contributes to head and neck cancer growth and resistance to EGFR targeting. Clin Cancer Res 12: 5064-5073, 2006.

14. Ekstrand AJ, Sugawa N, James CD and Collins VP: Amplified and rearranged epidermal growth factor receptor genes in human glioblastomas reveal deletions of sequences encoding portions of the N-and/or C-terminal tails. Proc Natl Acad Sci USA 89: 4309-4313, 1992.

15. Frederick L, Eley G, Wang XY and James CD: Analysis of genomic rearrangements associated with EGRFVIII expression suggests involvement of Alu repeat elements. Neuro Oncol 2: $159-163,2000$

16. Pines G, Huang PH, Zwang Y, White FM and Yarden Y: EGFRvIV: a previously uncharacterized oncogenic mutant reveals a kinase autoinhibitory mechanism. Oncogene 29: 5850-5860, 2010.

17. Cho J, Pastorino S, Zeng Q, Xu X, Johnson W, Vandenberg S, Verhaak R, Cherniack AD, Watanabe H, Dutt A, Kwon J, Chao YS, Onofrio RC, Chiang D, Yuza Y, Kesari S and Meyerson M: Glioblastoma-derived epidermal growth factor receptor carboxyl-terminal deletion mutants are transforming and are sensitive to EGFR-directed therapies. Cancer Res 71: 7587-7596, 2011.

18. Frederick L, Wang XY, Eley G and James CD: Diversity and frequency of epidermal growth factor receptor mutations in human glioblastomas. Cancer Res 60: 1383-1387, 2000.

19. Yoshimoto K, Dang J, Zhu S, Nathanson D, Huang T, Dumont R, Seligson DB, Yong WH, Xiong Z, Rao N, Winther H, Chakravarti A, Bigner DD, Mellinghoff IK, Horvath S, Cavenee WK, Cloughesy TF and Mischel PS: Development of a real-time RT-PCR assay for detecting EGFRvIII in glioblastoma samples. Clin Cancer Res 14: 488-493, 2008.

20. Newcomb EW, Cohen H, Lee SR, Bhalla SK, Bloom J, Hayes RL and Miller DC: Survival of patients with glioblastoma multiforme is not influenced by altered expression of p16, p53, EGFR, MDM2 or Bcl-2 genes. Brain Pathol 8: 655-667, 1998. 
21. Sonnweber B, Dlaska M, Skvortsov S, Dirnhofer S, Schmid T and Hilbe W: High predictive value of epidermal growth factor receptor phosphorylation but not of EGFRvIII mutation in resected stage I non-small cell lung cancer (NSCLC). J Clin Pathol 59: 255-259, 2006.

22. Nieto Y, Nawaz F, Jones RB, Shpall EJ and Nawaz S: Prognostic significance of overexpression and phosphorylation of epidermal growth factor receptor (EGFR) and the presence of truncated EGFRvIII in locoregionally advanced breast cancer. J Clin Oncol 25: 4405-4413, 2007.

23. Heimberger AB, Hlatky R, Suki D, Yang D, Weinberg J, Gilbert M, Sawaya R and Aldape K: Prognostic effect of epidermal growth factor receptor and EGFRvIII in glioblastoma multiforme patients. Clin Cancer Res 11: 1462-1466, 2005.

24. Aldape KD, Ballman K, Furth A, Buckner JC, Giannini C, Burger PC, Scheithauer BW, Jenkins RB and James CD: Immunohistochemical detection of EGFRvIII in high malignancy grade astrocytomas and evaluation of prognostic significance. J Neuropathol Exp Neurol 63: 700-707, 2004.

25. Mellinghoff IK, Wang MY, Vivanco I, Haas-Kogan DA, Zhu S, Dia EQ, Lu KV, Yoshimoto K, Huang JH, Chute DJ, Riggs BL, Horvath S, Liau LM, Cavenee WK, Rao PN, Beroukhim R, Peck TC, Lee JC, Sellers WR, Stokoe D, Prados M, Cloughesy TF, Sawyers CL and Mischel PS: Molecular determinants of the response of glioblastomas to EGFR kinase inhibitors. N Engl J Med 353: 2012-2024, 2005.

26. Li L, Dutra A, Pak E, Labrie JE, 3rd, Gerstein RM, Pandolfi PP, Recht LD and Ross AH: EGFRvIII expression and PTEN loss synergistically induce chromosomal instability and glial tumors. Neuro Oncol 11: 9-21, 2009.

27. Haas-Kogan DA, Prados MD, Lamborn KR, Tihan T, Berger MS and Stokoe D: Biomarkers to predict response to epidermal growth factor receptor inhibitors. Cell Cycle 4: 1369-1372, 2005.

28. Haas-Kogan DA, Prados MD, Tihan T, Eberhard DA, Jelluma N, Arvold ND, Baumber R, Lamborn KR, Kapadia A, Malec M, Berger MS and Stokoe D: Epidermal growth factor receptor, protein kinase B/Akt, and glioma response to erlotinib. J Natl Cancer Inst 97: 880-887, 2005.

29. van den Bent MJ, Brandes AA, Rampling R, Kouwenhoven MC, Kros JM, Carpentier AF, Clement PM, Frenay M, Campone M, Baurain JF, Armand JP, Taphoorn MJ, Tosoni A, Kletzl H, Klughammer B, Lacombe D and Gorlia T: Randomized phase II trial of erlotinib versus temozolomide or carmustine in recurrent glioblastoma: EORTC brain tumor group study 26034. J Clin Oncol 27: 1268-1274, 2009.

30. Jeuken J, Sijben A, Alenda C, Rijntjes J, Dekkers M, BootsSprenger S, McLendon R and Wesseling P: Robust detection of EGFR copy number changes and EGFR variant III: technical aspects and relevance for glioma diagnostics. Brain Pathol 19: 661-671, 2009.
31. Patel D, Lahiji A, Patel S, Franklin M, Jimenez X, Hicklin DJ and Kang X: Monoclonal antibody cetuximab binds to and down-regulates constitutively activated epidermal growth factor receptor vIII on the cell surface. Anticancer Res 27: 3355-3366, 2007.

32. Eller JL, Longo SL, Hicklin DJ and Canute GW: Activity of anti-epidermal growth factor receptor monoclonal antibody C225 against glioblastoma multiforme. Neurosurgery 51: 1005-1013, 2002.

33. Eller JL, Longo SL, Kyle MM, Bassano D, Hicklin DJ and Canute GW: Anti-epidermal growth factor receptor monoclonal antibody cetuximab augments radiation effects in glioblastoma multiforme in vitro and in vivo. Neurosurgery 56: 155-162, 2005.

34. Neyns B, Sadones J, Joosens E, Bouttens F, Verbeke L, Baurain JF, D'Hondt L, Strauven T, Chaskis C, In't Veld P, Michotte A and De Greve J: Stratified phase II trial of cetuximab in patients with recurrent high-grade glioma. Ann Oncol 20: 1596-1603, 2009.

35. Louis DN, Ohgaki H, Wiestler OD, Cavenee WK, Burger PC, Jouvet A, Scheithauer BW and Kleihues P: The 2007 WHO classification of tumours of the central nervous system. Acta Neuropathol 114: 97-109, 2007.

36. Lv S, Teugels E, Sadones J, Quartier E, Huylebrouck M, Du Four S, Le Mercier M, De Witte O, Salmon I, Michotte A, De Greve J and Neyns B: Correlation between IDH1 gene mutation status and survival of patients treated for recurrent glioma. Anticancer Res 31: 4457-4463, 2011.

37. Loupakis F, Pollina L, Stasi I, Ruzzo A, Scartozzi M, Santini D, Masi G, Graziano F, Cremolini C, Rulli E, Canestrari E, Funel N, Schiavon G, Petrini I, Magnani M, Tonini G, Campani D, Floriani I, Cascinu S and Falcone A: PTEN expression and KRAS mutations on primary tumors and metastases in the prediction of benefit from cetuximab plus irinotecan for patients with metastatic colorectal cancer. J Clin Oncol 27: 2622-2629, 2009.

38. Mason WP and Cairncross JG: Invited article: the expanding impact of molecular biology on the diagnosis and treatment of gliomas. Neurology 71: 365-373, 2008

39. Fults D and Pedone C: Immunocytochemical mapping of the phosphatase and tensin homolog (PTEN/MMAC1) tumor suppressor protein in human gliomas. Neuro Oncol 2: 71-79, 2000.

40. de Groot JF, Gilbert MR, Aldape K, Hess KR, Hanna TA, Ictech S, Groves MD, Conrad C, Colman H, Puduvalli VK, Levin V and Yung WK: Phase II study of carboplatin and erlotinib (Tarceva, OSI-774) in patients with recurrent glioblastoma. J Neurooncol 90: 89-97, 2008. 